\title{
Genetic and histological studies on the delayed systemic movement of Tobacco Mosaic Virus in Arabidopsis thaliana Carolina Serrano ${ }^{\dagger}$, Javiera González-Cruz ${ }^{\dagger}$, Francisca Jauregui, Consuelo Medina, Pablo Mancilla, José Tomás Matus and Patricio Arce- Johnson*
}

Address: Departamento de Genética Molecular y Microbiología, Pontificia Universidad Católica de Chile, Casilla 114-D. Santiago, Chile Email: Carolina Serrano - clserran@puc.cl; Javiera González-Cruz - javigonz@uchile.cl; Francisca Jauregui - fajauregui@gmail.com; Consuelo Medina - cmedina@bio.puc.cl; Pablo Mancilla - pmancill@puc.cl; José Tomás Matus - tomas.matus@gmail.com; Patricio ArceJohnson* - parce@bio.puc.cl

* Corresponding author †Equal contributors

Published: 26 September 2008

BMC Genetics 2008, 9:59 doi:10.1 186/1471-2156-9-59
Received: 27 March 2008

Accepted: 26 September 2008

This article is available from: http://www.biomedcentral.com/I47I-2I56/9/59

(C) 2008 Serrano et al; licensee BioMed Central Ltd.

This is an Open Access article distributed under the terms of the Creative Commons Attribution License (http://creativecommons.org/licenses/by/2.0), which permits unrestricted use, distribution, and reproduction in any medium, provided the original work is properly cited.

\begin{abstract}
Background: Viral infections and their spread throughout a plant require numerous interactions between the host and the virus. While new functions of viral proteins involved in these processes have been revealed, current knowledge of host factors involved in the spread of a viral infection is still insufficient. In Arabidopsis thaliana, different ecotypes present varying susceptibilities to Tobacco mosaic virus strain UI (TMV-UI). The rate of TMV-UI systemic movement is delayed in ecotype Col- 0 when compared with other 13 ecotypes.
\end{abstract}

We followed viral movement through vascular tissue in Col-0 plants by electronic microscopy studies. In addition, the delay in systemic movement of TMV-UI was genetically studied.

Results: TMV-UI reaches apical leaves only after 18 days post rosette inoculation (dpi) in Col-0, whereas it is detected at 9 dpi in the Uk-4 ecotype. Genetic crosses between Col-0 and Uk-4 ecotypes, followed by analysis of viral movement in $F_{1}$ and $F_{2}$ populations, revealed that this delayed movement correlates with a recessive, monogenic and nuclear locus. The use of selected polymorphic markers showed that this locus, denoted DSTMI (Delayed Systemic Tobamovirus Movement I), is positioned on the large arm of chromosome II. Electron microscopy studies following the virion's route in stems of Col- 0 infected plants showed the presence of curved structures, instead of the typical rigid rods of TMV-UI. This was not observed in the case of TMVUI infection in Uk-4, where the observed virions have the typical rigid rod morphology.

Conclusion: The presence of defectively assembled virions observed by electron microscopy in vascular tissue of Col- 0 infected plants correlates with a recessive delayed systemic movement trait of TMV-UI in this ecotype. 


\section{Background}

Systemic viral infections in plants are complex processes that require compatible virus-host interactions in multiple tissues. These interactions include: viral genome replication in the cytoplasm of the initially infected cells, cellto-cell movement towards neighboring tissues, long-distance movement through the vascular tissue, phloem unloading and cell-to-cell movement in non-inoculated systemic tissues [1]. Incompatibilities between virus and host factors at any of these stages could therefore lead to restrictions and delays establishment of a systemic infection.

The Tobacco mosaic virus TMV-U1 has been one of the most useful viruses for elucidating the steps of viral infections in experimental plant systems $[2,3]$. The TMV genome encodes four proteins which participate in several viral functions required for a successful infection. Recent studies have shown that replication and movement of viral complexes in infected tobacco tissues are strongly associated with plant structures such as the endoplasmic reticulum and the cytoskeleton [4-6].

Viral infections in plants have been studied in the model plant Arabidopsis thaliana, due to the genetic and genomic knowledge of this specie. This model has proven to be useful in elucidating the relationship between the host plant and both the virus replication and movement processes [7,8]. Several Arabidopsis ecotypes display differential susceptibilities towards specific viral infections. This has led to the identification of various loci involved in development of viral infections. For example, some host loci responsible for resistance against viral infections have been located in this model [9-11]. Among these, different genes related to the cell cycle $[12,13]$ and viral movement have been identified $[14,15]$. Nevertheless, the relationship between host proteins encoded by these genes and viral factors involved in these interactions are still an active research issue [13].

In previous works, we evaluated the systemic infection of TMV-U1 in fourteen ecotypes of Arabidopsis thaliana using in vitro grown plants [16]. Important differences in the rate of the systemic infection were found among these ecotypes; some, such as Uk-4 became infected at a very fast rate, while others, for example Col-0, became infected very slowly. With the aim of studying this natural variance of Arabidopsis ecotypes, we searched for the genetic basis that could explain the differences in viral systemic infection rates in Arabidopsis thaliana. For this purpose Uk-4 and Col-0 ecotypes were selected. Genetic crosses were performed between plants of both ecotypes and the resulting progeny was analysed with genetic markers to localize the trait conferring this delay within Col-0. Electron microscopy was employed to identify the tissues in which the virus spread was delayed.

\section{Methods}

\section{Plant growing and genetic crosses}

Arabidopsis thaliana ecotypes Columbia-0 (Col-0) and Umkirch-4 (Uk-4) were grown in soil in a controlled environment growth chamber. Col-0 and Uk-4 crosses were carried out according to the method described by Guzmán and Ecker [17] to obtain the $\mathrm{F}_{1}$ progeny. Crosses ( $(+) \mathrm{Uk}-4$ $\times\left(O^{7}\right) \mathrm{Col}-0$ and reciprocal crosses $(+) \mathrm{Col}-0 \times\left(O^{7}\right) \mathrm{Uk}-4$ were also performed. $\mathrm{F}_{1}$ plants derived from these crosses were grown in soil under controlled conditions and selfpollinated to obtain $\mathrm{F}_{2}$ populations.

\section{Virus stocks and plant inoculation}

Virus stocks of TMV-U1 and TMV-Cg were prepared from systemically infected Nicotiana tabacum cvXanthi nn plants as described by Bruening et al. [18], and stored in TE-virus buffer (Tris-HCl $10 \mathrm{mM}$, EDTA $1 \mathrm{mM} \mathrm{pH} \mathrm{7.2)} \mathrm{at}$ $4^{\circ} \mathrm{C}$.

Arabidopsis thaliana ecotypes Col-0 and Uk-4, as well as $\mathrm{F}_{1}$ and $\mathrm{F}_{2}$ plants were grown in vitro on half MS solid medium in a climate chamber $\left[25^{\circ} \mathrm{C}, 16 / 8\right.$-h (light/dark) photoperiod]. Six-week-old plants with inflorescences were mechanically inoculated on three rosette leaves with a 10 $\mu \mathrm{g} / \mathrm{ml}$ virus solution in $20 \mathrm{mM}$ phosphate buffer $\mathrm{pH}$ 7.0, using a sterile cotton swab dusted with carborundum.

\section{Immunological detection of TMV-UI in infected plants}

Virus presence in plant tissues was detected by Western blot and ELISA using a virus coat protein (CP) antibody [19]. For Western blot experiments, both inoculated and apical leaves of parents, $\mathrm{F}_{1}$ and $\mathrm{F}_{2}$ populations were harvested at $12 \mathrm{dpi}$. Fresh Arabidopsis leaves $(50 \mathrm{mg}$ ) were macerated with $100 \mu$ l of extraction buffer (125 mM Tris$\mathrm{HCl} \mathrm{pH} 6.8,0.1 \%$ SDS and $20 \% \mathrm{v} / \mathrm{v}$ glycerol), debris was removed by centrifugation at $10.000 \mathrm{~g}$ for 10 minutes and $30 \mu \mathrm{g}$ of total protein were denatured at $95^{\circ} \mathrm{C}$, and separated by $12 \%$ polyacrylamide-SDS gel electrophoresis. Proteins were transferred to a nitrocellulose membrane $(0,45 \mu \mathrm{M}$, Amersham Life Science). Blots were blocked with skim milk and then incubated with a rabbit polyclonal antibody against TMV-U1 CP diluted at 1:1000, as previously described by Arce-Johnson et al. [16]. Finally, CP was revealed using conjugated alkaline phosphatase-goat anti-rabbit IgG (ImmunoPure Antibody, Pierce, USA) diluted to 1:20.000 and alkaline phosphatase activity was revealed with "Phosphatase substrate 3-C" (KPL, Maryland, USA).

ELISA assays were performed as described by Pereda et al. [19]. Pools of apical leaves from eight plants were homogenized in carbonate buffer at $\mathrm{pH}$ 9.6, and total proteins 
were measured by BCA protein assay reagent A (Pierce, Rockford, USA). Plates were incubated overnight with 100 $\mu \mathrm{g}$ of leaf extract supernatants. Primary antibodies [16] and alkaline phoshatase conjugate (goat anti-rabbit IgG, Pierce, USA) were diluted to 1:500. The enzymatic reaction was incubated for $60 \mathrm{~min}$ at $37^{\circ} \mathrm{C}$, using $1 \mathrm{mg} / \mathrm{mL}$ of 4-paranitrophenyl-phosphate (Merck) as a substrate. Optical density was measured at $\lambda=405 \mathrm{~nm}$ in an ELISA microwell reader (Metertech $\Sigma 960$, Austria). Relative CP was obtained as the ratio of the absorbance of each sample to the maximum absorbance in the plate corresponding to an inoculated leaf at 10 dpi sample.

\section{Leaf skeleton hybridization}

Inoculated and apical Arabidopsis leaves were collected at $10 \mathrm{dpi}$ and prepared for hybridisation as described by Lartey et al. [20]. Briefly, chlorophyll was removed from leaves using 95\% ethanol and proteins were digested with proteinase $\mathrm{K}$ at $45^{\circ} \mathrm{C}$ for 3 hours. Leaves were incubated in a prehybridisation solution consisting of $6 \times$ SSPE, $50 \%$ formamide, $5 \times$ Denhardt's solution, $0.5 \%$ SDS and $20 \mathrm{ug} /$ ml salmon sperm DNA at $42^{\circ} \mathrm{C}$ for $2 \mathrm{~h}$. A denatured $32 \mathrm{P}$ labeled probe was added and kept overnight. This probe consisted of a PCR product of 518 bp corresponding to the TMV-U1 CP gene. Leaves were washed twice at $42^{\circ} \mathrm{C}$ in $2.5 \times$ SSC, rinsed in distilled water, carefully fixed to a nitrocellulose membrane and then autoradiographed. Three independent experiments were carried out inoculating four plants of each ecotype. Mock inoculated leaves were also used in hybridization experiments as negative controls.

\section{Electron Microscopy}

Inoculated leaves, petioles, stems and apical leaves from non-infected and infected plants were prepared for electron microscopy. Tissue samples of $0.5 \mathrm{~cm}$ were taken from plants after 10,12 and $18 \mathrm{dpi}$. Tissues were fixed in $0.1 \mathrm{M}$ sodium cacodylate-buffer ( $\mathrm{pH} 7.2$ ) with $3 \%$ glutaraldehyde for $3 \mathrm{~h}$ at room temperature according to Lartey et al. [20]. Samples were washed in $0.1 \mathrm{M}$ cacodylate buffer for $1 \mathrm{~h}$, dehydrated in an acetone gradient $(50,70$, 95 and $100 \%$ ) and embedded in a freshly prepared Embed 812 (EM Sciences, Fort Washington, USA). After overnight polymerization at $60^{\circ} \mathrm{C}$, thin sections $(70-80$ $\mathrm{nm}$ ) were cut using a Sorvall MT2-B ultramicrotome. Samples were stained in methanol $4 \%$ uranyl acetate [21] followed by $0.1 \%$ lead citrate [22] and examined under a Philips Model Tecnai 12 transmission electron microscope. Images were revealed on $6.5 \times 9.0$ Kodak SO163 film.

\section{Genetic Analysis}

Polymorphisms among the parental ecotypes Col-0 and Uk-4 were studied testing 79 cleaved amplified polymorphic sequences (CAPS) and 53 simple sequence length polymorphisms (SSLP) (Research Genetic, Hunsville, USA), covering all five Arabidopsis chromosomes. Information on the CAPS and SSLP markers were obtained from The Arabidopsis Information Resource (TAIR; http:/ /www.arabidopsis.org/) and The Bio-Array Resource for Arabidopsis Functional Genomics (BAR; http://bar.uto ronto.ca/markertracker). Other markers were also obtained from Muramoto et al., [23] and Matsumoto and Okada [24]. Genomic DNA was prepared and small scale PCRs were carried out according to Konieczny and Ausubel [25] for CAPS and according to Bell and Ecker [26] for SSLP. Markers that were polymorphic among both ecotypes were selected for mapping. Mapping was done using the individuals of the $\mathrm{F}_{2}$ population which showed delay in TMV-U1 systemic movement detected by Western blot at 12 dpi. Initially, five polymorphic molecular markers for each of the five Arabidopsis chromosomes were used. Recombination frequency between the locus and the molecular marker was calculated by dividing the number of recombinant chromatids by the total number of chromatids. For chromosome II, 25 additional polymorphic markers were used in order to map the locus with a higher resolution.

\section{Results \\ Differential time-course of TMV-UI systemic infection in Col-0 and Uk-4 ecotypes}

In situ hybridization was used to compare virus accumulation in inoculated and systemic leaves of Arabidopsis ecotypes Uk-4 and Col-0. As expected, viral RNA was present in apical leaves of Uk-4 at $10 \mathrm{dpi}$, but not in those from the Col-0 ecotype (Figure 1a) even when inoculated leaves of both ecotypes were completely infected at this time point (Figure 1a). This result confirms the Uk-4 and Col0 differences in viral systemic movement as was previously described by Arce-Johnson et al. 2000 [16].

To discard that delayed systemic movement in Col-0 was due to a difference in local virus movement, we monitored the time course of the infection in the inoculated leaf for both ecotypes. TMV-CP was detected by Western blot in the inoculated basal leaves starting from $4 \mathrm{dpi}$ in both ecotypes, indicating that the local movement of the virus is not affected by the genetic background (Figure 1b).

Viral systemic movement was further studied by ELISA (Figure 1c). In apical leaves of Uk-4, TMV CP is present starting from $9 \mathrm{dpi}$, while in Col-0, CP is detectable in these leaves only after $18 \mathrm{dpi}$. Based on these results, we decided to analyse genetic experimental populations in order to distinguish delayed and susceptible phenotypes in the next steps at $12 \mathrm{dpi}$, a time point in which the differences in viral CP accumulation in distal apical leaves was clearly evident between Uk-4 and Col-0 ecotypes. 
$\mathbf{a}$
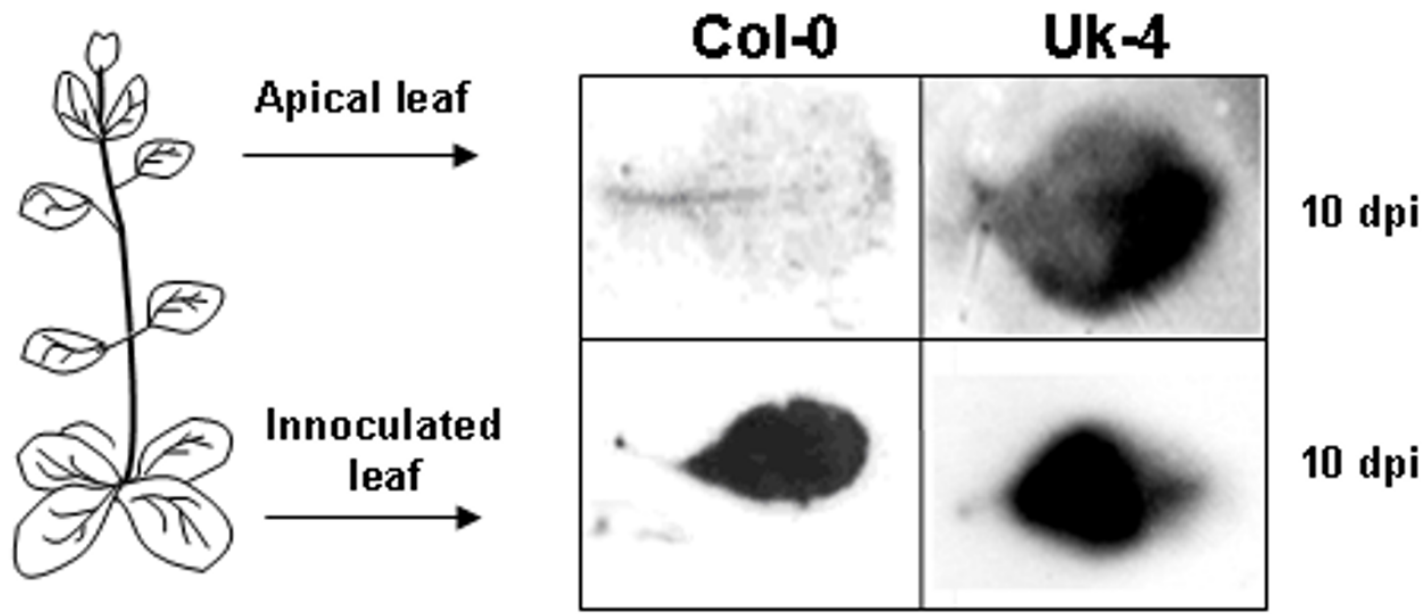

\section{b Innoculated leaf}

C

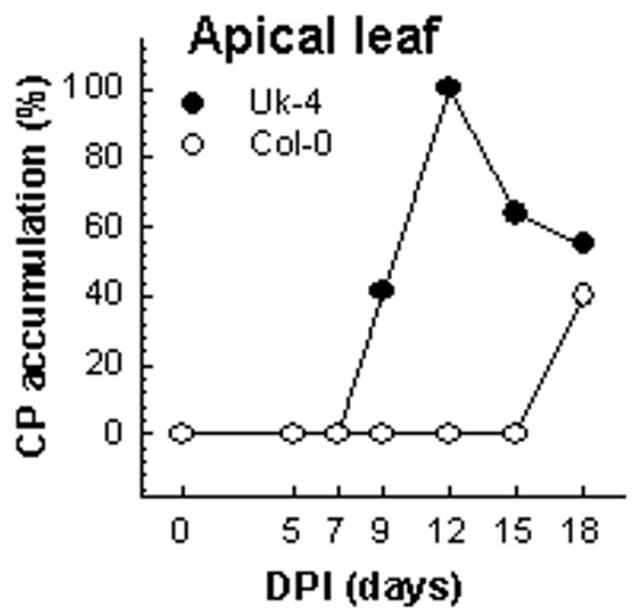

Figure I

Differential systemic movement of TMV-UI in two Arabidopsis thaliana ecotypes. Col-0 and Uk-4 plants were mechanically inoculated on three rosette leaves with a solution of $10 \mathrm{ng} / \mu \mathrm{l}$ of virus diluted in $20 \mathrm{mM}$ phosphate buffer. (a) In situ hybridisation of inoculated and apical leaves from infected plants at $10 \mathrm{dpi}$. Leaves were incubated with a TMV-UI coat protein DNA probe. The virus coat protein gene was detected ubiquitously in inoculated leaves from both ecotypes, but only in an apical leaf of Uk-4 plants. Images represent equivalent levels of exposure to film. (b) Western blot showing similar time-courses of TMV-UI infection in inoculated leaves of Col-0 (upper) and Uk-4 (bottom) plants. Coat protein is evident in both cases starting from $4 \mathrm{dpi}$. (c) ELISA showing differences in the systemic spread of TMV-UI in Col-0 and Uk-4 plants. Apical leaves of inoculated plants were analysed for $18 \mathrm{dpi}$.

\section{Curved particles of TMV-UI appear in the vascular stem tissues in Col-0 \\ Viral movement from the inoculated leaves to the vascular system and then into apical tissues was followed using electron microscopy (Figure 2). Accumulation of TMV-U1 particles in mesophyll cells of Col-0 inoculated leaves was evident at 10 dpi (Figure 2a); however, virions were not observed in the stem, petioles or mesophyll cells of apical leaves at this time point (Figure 2b, c, d). In contrast, a large number of virions were observed in the stem and mesophyll of apical leaves of the Uk-4 ecotype at $10 \mathrm{dpi}$ (Figure 2e and 2f).}

Since the virus is detected in Col-0 apical tissues only after 18 dpi (Figure 1c) [16], cross sections of the vascular zone of rosette leaves, stems and apical leaves were studied at this time point. Surprisingly, curved virions, similar in length to the rigid viral rods $(300 \mathrm{~nm})$ were observed in the vascular tissue of the stem (Figure 3a) and in apical leaf petioles (3b). Similar structures were observed in the stems of Col-0 plants in three independent experiments. These could correspond to defectively assembled virions or different associations of viral proteins. However, in the mesophyll cells of apical leaves, normal rigid rods of TMV-U1 were observed (Figure 3c). On the other hand, in 


\section{Col-0 (10 dpi)}
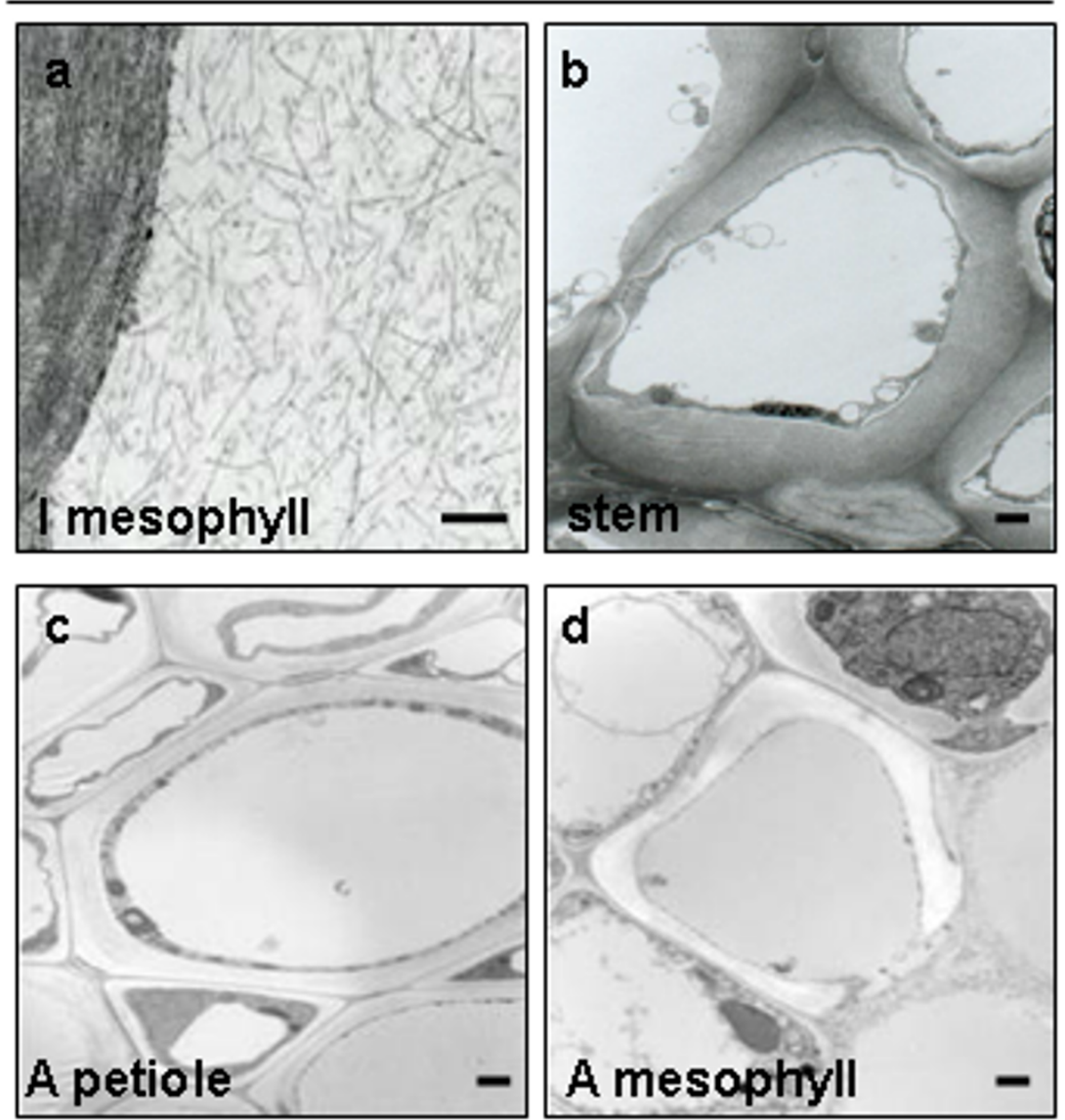

Uk-4 (10 dpi)
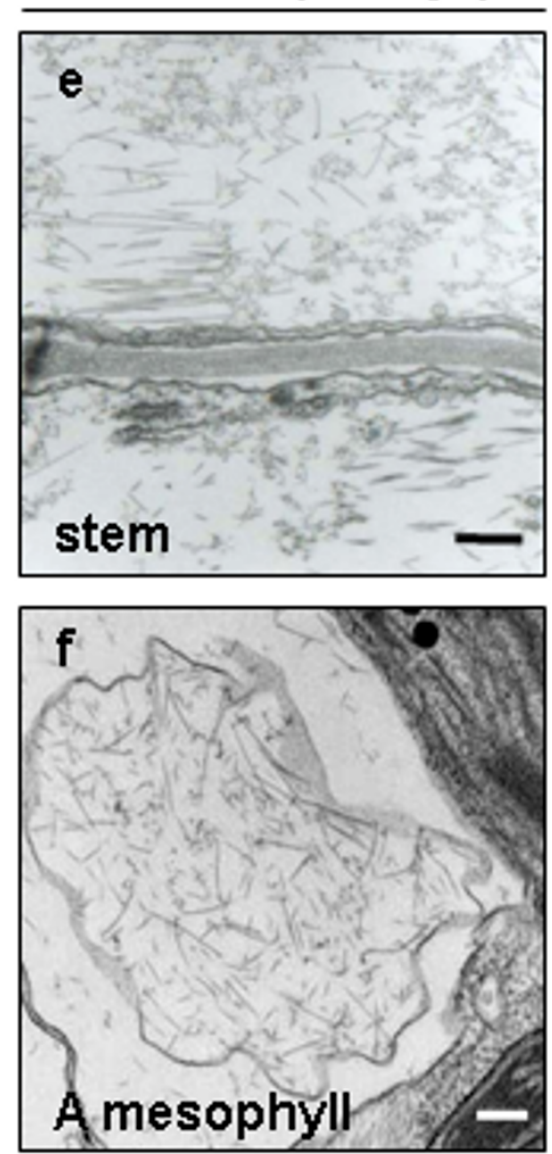

\section{Figure 2}

TMV-UI particles appear in the inoculated leaves but not in the stems or apical tissues of Col-0 at 10 dpi. Electron microscopy images showing high accumulation of virions in mesophyll cells of Col-0 inoculated leaves (a), and absence of these particles in vascular tissue of the stem (b), petiole (c) and mesophyll cells of apical leaves (d). In Uk-4 ecotype, at this time, high viral accumulation is shown in the stem (e) and mesophyll cells of apical leaves (f). Bars: $100 \mu \mathrm{m}$.

the case of Uk-4 infected plants, the stem (3d) and the apical leaf petioles (3e) harboured rigid viral rods. To evaluate if the curved virions appeared when different Tobamoviruses infect Col-0 plants, the crucifer infecting TMV-Cg was tested. TMV-Cg efficiently infects several Arabidopsis ecotypes and in this case normal shaped virions were always found in the vascular tissue of rosette leaves, stems and apical leaves (Figure 3f).

To investigate if the curved particles were still infective, crude extracts of stem tissues from TMV-U1 infected Col0 plants were used to inoculate tobacco Nicotiana tabacum plants. Local necrotic lesions developed in tobaco plants carrying the TMV-resistant $N$ gene while systemic infection occurred in sensitive plants lacking the $N$ gene, indicating that these particles were still infectious (data not shown).
The systemic TMV-UI movement delay trait in the Col-0 ecotype is recessive and nuclear

To determine the genetic basis of the delayed movement of TMV-U1 virions in the Col-0 ecotype, crosses were performed between Col-0 and Uk-4 plants. From the 132 molecular markers used (CAPS and SSLP), 45 were found to be polymorphic (Table 1). Among them, four belonged to chromosome I, 25 to chromosome II, six to chromosome III, four to chromosome IV, and seven to chromosome V (Table 1).

To confirm the crosses between Col-0 and Uk-4, polymorphic molecular markers for the five chromosomes were tested in plants from the $\mathrm{F}_{1}$ population. All $\mathrm{F}_{1}$ tested plants resulted heterozygous, confirming that the crosses were effective (not shown). Sixty plants belonging to the $\mathrm{F}_{1}$ $\left[(\right.$ O $)$ Uk-4 $\times\left(O^{7}\right)$ Col-0] population and 50 plants 


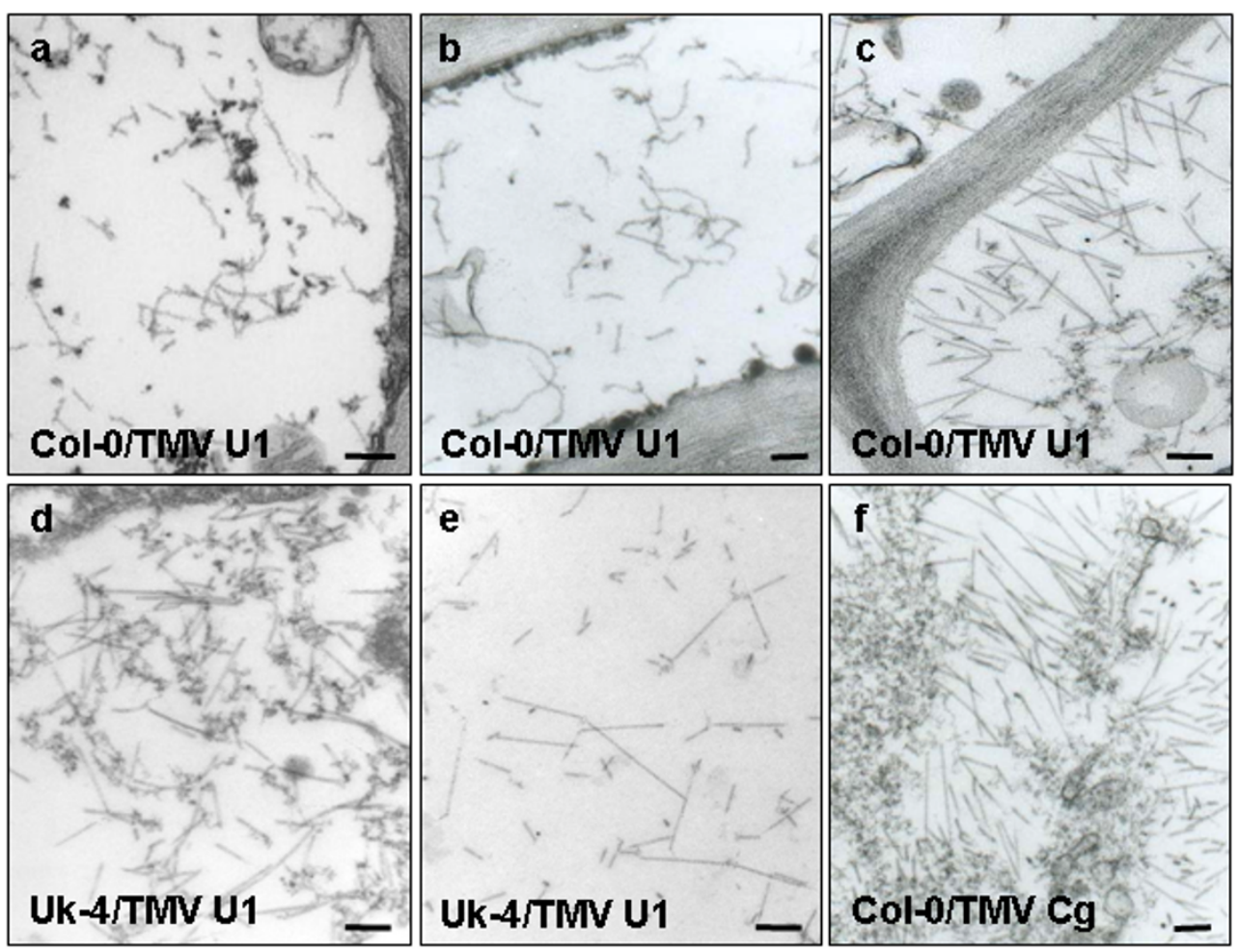

\begin{abstract}
Figure 3
Curved TMV-UI virions accumulate in the vascular tissues of infected Col-0 plants. Electron microscopy images of virus infected tissues in Col- 0 and Uk-4 plants were taken at $18 \mathrm{dpi}$. Curved virions are evident in the vascular tissue of the stem (a) and petiole of apical leaves (b), but normal rigid rod virions appear in the mesophyll of apical leaves (c). Rigid rod virions appear in the stem (d) and petiole of apical leaves (e) in Uk-4 plants. An image of Col-0 vascular cells infected with the TMV-Cg strain was included as a control $(\mathrm{f})$. Bars: $100 \mu \mathrm{m}$.
\end{abstract}

obtained by the reciprocal crossing [( +$)$ Col- $\left.0 \times\left(O^{1}\right) \mathrm{Uk}-4\right]$ were used to screen viral movement. Three rosette leaves of each plant were inoculated with TMV-U1, and samples from both apical and inoculated leaves were taken at 12 dpi. These tissues were analyzed by Western blot to detect TMV-U1 CP presence. All $\mathrm{F}_{1}$ infected plants accumulated TMV-U1 CP in the apical leaves at $12 \mathrm{dpi}$, indicating that the susceptible phenotype (Uk-4) is dominant over the "delay in systemic movement" phenotype. These $\mathrm{F}_{1}$ plants were then self-pollinated, and 277 plants of the $\mathrm{F}_{2}$ population were evaluated for TMV-U1 movement. As an example, analysis of ten $\mathrm{F}_{2}$ population plants is shown in Figure 4. Accumulation of TMV-U1 CP was examined in the inoculated rosette leaves and in the systemic apical leaves. 198 plants became systemically infected at $12 \mathrm{dpi}$, while 79 showed delayed systemic movement similar to that of the Col-0 parental ecotype (Table 2). A subsequent analysis of $112 \mathrm{~F}_{2}$ plants originating from reciprocal crosses revealed that 82 were systemically infected at 12 dpi and 30 showed a delayed infection (Table 2). These results indicate that the delay in systemic TMV-U1 move- ment is a recessive trait, probably controlled by a single, monogenic and nuclear locus. This locus was named DSTM1 for Delayed Systemic Tobamovirus Movement 1.

\section{Mapping DSTMI}

For genetic mapping analysis of the DSTM1 locus, $\mathrm{F}_{2}$ progeny plants from the UK- $4 \times$ Col- 0 cross were used. Fifty two TMV-U1 resistant individuals selected for absence of $\mathrm{CP}$ in non-inoculated upper leaves at $12 \mathrm{dpi}$ were screened. Co-segregation of this character with different polymorphic molecular markers was studied for each of the five A. thaliana chromosomes. In an initial analysis, using four or five polymorphic markers for each chromosome, the lowest recombination percentages obtained were: chromosome I $51.4 \%$ with nga 280 , chromosome II $36.5 \%$ with nga 168 , chromosome III $51.4 \%$ with nga 172 , chromosome IV 50\% with AG and chromosome V $56.8 \%$ with nga 129 . Recombination frequencies between DSTM1 locus and the markers on chromosome II were less than $50 \%$, strongly suggesting that DSTM1 is located in this chromosome. For further mapping analysis, 21 
Table I: Polymorphic markers in Col-0 and Uk-4 ecotypes used to map the DSTMI locus

\begin{tabular}{|c|c|c|c|c|c|c|}
\hline Marker & Chr & Type & Enzyme & Primer Forward $\left(5^{\prime} \rightarrow 3^{\prime}\right)$ & Primer Reverse $\left(5^{\prime} \rightarrow 3^{\prime}\right)$ & Reference \\
\hline m305 & 1 & CAPS & Haelll & TGAAGCTAATATGCACAGGAG & TTCTCCAGACCACATGATTAT & TAIR \\
\hline gl I447 & I & CAPS & EcoRV & CAGTGTGTATCAAAGCACCA & GTGACAGACTTGCTCCTACTG & TAIR \\
\hline nga59 & 1 & SSLP & - & TTAATACATTAGCCCAGACCCG & GCATCTGTGTTCACTCGCC & TAIR \\
\hline nga280 & I & SSLP & - & GGCTCCATAAAAAGTGCACC & CTGATCTCACGGACAATAGTGC & TAIR \\
\hline T27EI3 & II & CAPS & Nlalll & GGAATCATCGCTTGACGACTCC & GGACTTTTCGCCGTGAAGTCG & BAR \\
\hline $\mathrm{ML}$ & II & CAPS & Snabl & $\begin{array}{c}\text { CGGAAACACGAAGCTGATGAGT } \\
\text { TGGG }\end{array}$ & $\begin{array}{c}\text { CGAGAACAAAATGTGTACGGTG } \\
\text { TG }\end{array}$ & TAIR \\
\hline T9D9 & II & CAPS & Mbol & GGTCTCTTTGTCGCAACACTCC & $\begin{array}{c}\text { CATGAATGTTGTTTCCAAGTATC } \\
\text { C }\end{array}$ & TAIR \\
\hline ER & II & CAPS & Ddel & $\begin{array}{c}\text { GAGTTTATTCTGTGCCAAGTCCC } \\
\text { TG }\end{array}$ & $\begin{array}{c}\text { CTAATGTAGTGATCTGCGAGGTA } \\
\text { ATC }\end{array}$ & TAIR \\
\hline GBF3 & II & CAPS & HindIII & $\begin{array}{c}\text { AGCGAAGAAAATCACCCAAAGA } \\
\text { CAGACTC }\end{array}$ & $\begin{array}{l}\text { CTCATTTCATTCTGTTTCTCCGT } \\
\text { CAAGTG }\end{array}$ & TAIR \\
\hline Ks450 & II & CAPS & Hpall & $\begin{array}{c}\text { CGGTAGCCGATCCTGATTTGATC } \\
\text { AG }\end{array}$ & $\begin{array}{c}\text { TTCCTTATCTCCTTGTCTAACTT } \\
\text { CC }\end{array}$ & Muramoto et al. (1999) \\
\hline $\mathrm{nmF}$ & II & CAPS & BstXI & $\begin{array}{c}\text { GGTTTATCACCAAACCAGTTTAT } \\
\text { TG }\end{array}$ & TTGTTTGTTCGGGTCTCTCC & Matsumoto \& Okada (200I) \\
\hline $\mathrm{nmG}$ & II & CAPS & EcoRV & GGACAGGTAAGAGACAGTAG & AGAAGAGGAGCGTGTATGCT & Matsumoto \& Okada (200I) \\
\hline Ve017 & II & CAPS & Pstl & GAGCAATCCAGTAGAGGATA & CTTGAAGCTTAAATCTCAGC & TAIR \\
\hline 11444 & II & CAPS & EcoRV & CCGGTTTTCGTTCCTGTGTA & $\begin{array}{c}\text { CTAAGATCAACCACTGTCCTAG } \\
C\end{array}$ & BAR \\
\hline EMBII87 & II & CAPS & Pstl & AACCTCAGCTGTGGGTTGAT & CATCATTCAGCATGAAGTTTCC & BAR \\
\hline 11697 & II & CAPS & Hpall & $\begin{array}{c}\text { ATGGGAAGCAAAGCTATTGTATC } \\
\text { AG }\end{array}$ & AACGTTGGAGAGAGACGACA & BAR \\
\hline FI5K20.13 & II & CAPS & EcoRI & CACTTCTTCATCGCCGTCTG & САССТССТССАССТССАGАT & BAR \\
\hline ATIPT2 & II & CAPS & EcoRV & $\begin{array}{l}\text { TTTAAGAATTTTGAAGTCCTATA } \\
\text { CGTT }\end{array}$ & TCAAGAAACTGTTGTGACTGGA & BAR \\
\hline F24DI3.7 & II & CAPS & Dral & GAACTCATTGCCAAAGACGA & TCACAGTGAACCCTCTTCCTG & BAR \\
\hline TI7DI2.4 & II & CAPS & EcoRV & $\underset{G}{\text { CAACCACTTATTTGGTACAAGGT }}$ & СTTTTCCAAAGTGCTTACCACA & BAR \\
\hline 12185 & II & CAPS & HindIII & CTCGTGGGTTGCGAAAAG & $\underset{\text { CAGAGCTCTTCATCTTCATCTTC }}{\text { A }}$ & BAR \\
\hline ngal | 45 & II & SSLP & - & GCACATACCCACAACCAGAA & ССТTCACATCCAAAACCCAC & TAIR \\
\hline nga I 68 & II & SSLP & - & GAGGACATGTATAGGAGCCTCG & TCGTCTACTGCACTGCCG & TAIR \\
\hline ciw3 & ॥ & SSLP & - & GAAACTCAATGAAATCCACTT & TGAACTTGTTGTGAGCTTTGA & TAIR \\
\hline PLS3 & II & SSLP & - & TAGTCGTTTCTCTGGTTGTAG & TTGCCTGTCGATGTAGATTTGT & TAIR \\
\hline PLS7 & II & SSLP & - & GATGAATCTTCTCGTCCAAAAT & $\underset{T}{\text { GACAAACTAAACAACATCCTTCT }}$ & TAIR \\
\hline PLS9 & II & SSLP & - & GAAATTACGCCGAAAGGTC & CGTCACGAGAGGCACATC & TAIR \\
\hline CZSOD2 & II & SSLP & - & GAATCTCAATATGTGTCAAC & GCATTACTCCGGTGTCGTC & TAIR \\
\hline $\mathrm{C} 4 \mathrm{H}$ & II & SSLP & - & GTTCATGGACGGATGTGTATGC & CTAGTGGTGGTTAAAATATACGC & TAIR \\
\hline g47II & III & CAPS & HindIII & $\begin{array}{c}\text { CCTGTGAAAAACGACGTGCAGTT } \\
\text { TC }\end{array}$ & $\begin{array}{c}\text { ACCAAATCTTCGTGGGGCTCAG } \\
\text { CAG }\end{array}$ & TAIR \\
\hline Arlim I5.I & III & CAPS & EcoRI & $\begin{array}{c}\text { TGCTGCTTTATTTTGTCGCGATG } \\
\text { TT }\end{array}$ & $\begin{array}{c}\text { GCCAGTTTTTTCCTGCACATCAA } \\
\text { TC }\end{array}$ & TAIR \\
\hline GAPC & III & CAPS & EcoRV & ACGGAAAGACATTCCAGTC & CTGTTATCGTTAGGATTCGG & TAIR \\
\hline Ngal72 & III & SSLP & - & CATCCGAATGCCATTGTTC & AGCTGCTTCCTTATAGCGTCC & TAIR \\
\hline ngal I2 & III & SSLP & - & СТСТССАССТССТССАGTAСС & TAATCACGTGTATGCAGCTGC & TAIR \\
\hline ngal2 & III IV & SSLP & - & TGATGCTCTCTGAAACAAGAGC & AATGTTGTCСTCСССТССTC & TAIR \\
\hline AG & IV & CAPS & Xbal & CAAACACCATTTAATCTTGACA & CAACAGGTTTCTTCTTCTTCTC & TAIR \\
\hline g8300 & IV & CAPS & HindIII & GGCGGCACTGGTGGTGTAGG & $\underset{C}{\text { GTTGTCCCCTGTTAAAAGGAGC }}$ & TAIR \\
\hline ngal I 39 & IV & SSLP & - & TAGCCGGATGAGTTGGACC & TTTTTCCTTGTGTTGCATTCC & TAIR \\
\hline EG7F2 & $\mathrm{V}$ & CAPS & Xbal & $\underset{C}{\operatorname{GCATAGAATTTGACGATAACGAG~}}$ & GATCTGTGTAGGACTACGAGAC & TAIR \\
\hline $\mathrm{PLCl}$ & $\mathrm{V}$ & CAPS & HindIII & GAATCAGCCATTATCGCATTAC & GGGAACTCAAACTCCTTGTCC & TAIR \\
\hline ngal58 & $\mathrm{V}$ & SSLP & - & ACCTGAACCATCCTCCGTC & TCATTTTGGCCGACTTAGC & TAIR \\
\hline nga 129 & $\mathrm{~V}$ & SSLP & - & CACACTGAAGATGGTCTTGAGG & TCAGGAGGAACTAAAGTGAGGG & TAIR \\
\hline ngal5I & $\mathrm{V}$ & SSLP & - & $\underset{G}{\text { CAGTCTAAAAGCGAGAGTATGAT }}$ & GTTTTGGGAAGTTTTGCTGG & TAIR \\
\hline AThPhyC & $\mathrm{V}$ & SSLP & - & $\underset{T}{\text { CTCAGAGAATTCCCAGAAAAATC }}$ & $\underset{C}{\text { AAACTCGAGAGTTTGTCTAGAT }}$ & TAIR \\
\hline $\operatorname{ciw} 10$ & $\mathrm{~V}$ & SSLP & - & ССАСАТTTTССТTСТTTСАТА & CAACATTTAGCAAATCAACTT & TAIR \\
\hline
\end{tabular}




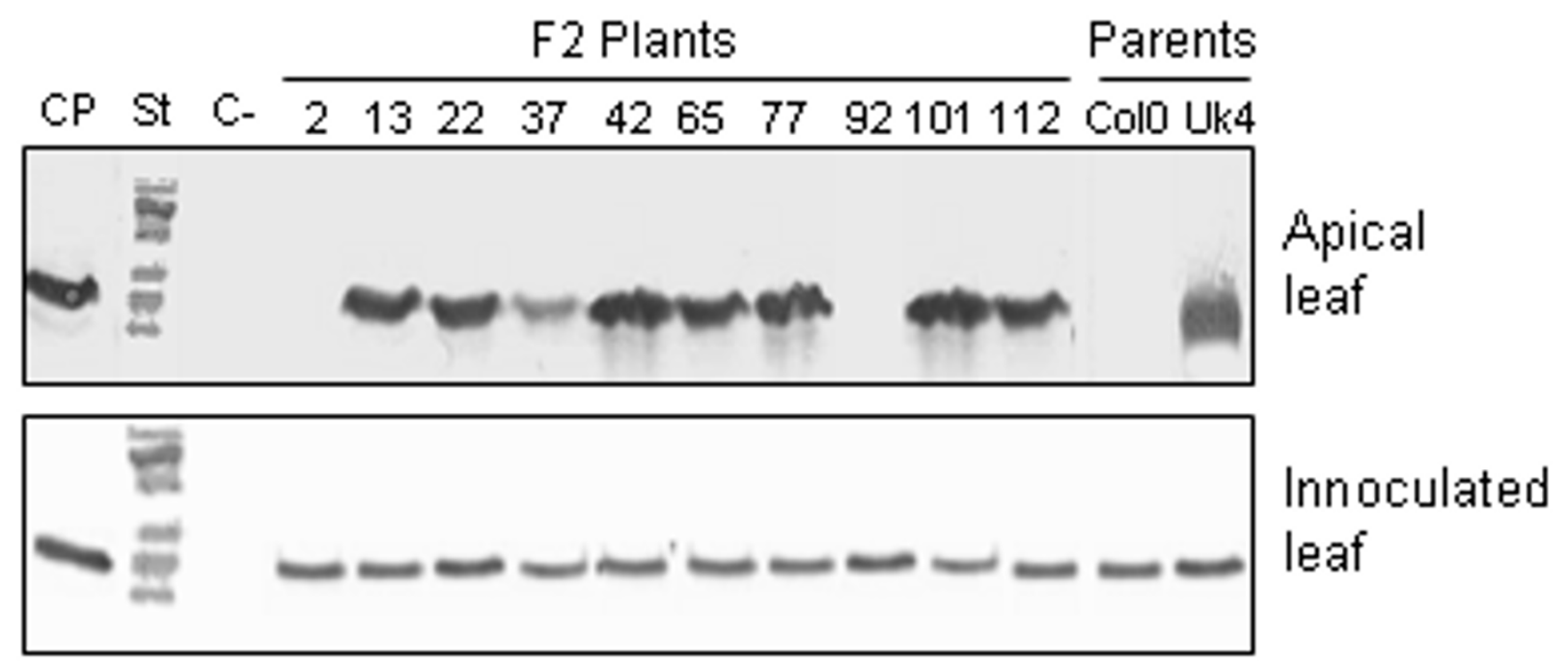

Figure 4

Systemic movement of TMV-UI in the F2 population. Analysis of systemic movement by Western blot in several plants of the F2 population is exemplified. The TMV-UI coat protein was detected in the inoculated rosette leaves of all plants analysed and in apical leaves of most plants. This analysis was carried out for each of the F2 plants that appear in Table 2. CP: coat protein, St: molecular weight standard, C-: negative control (non-inoculated leaves).

additional chromosome II CAPS markers were used. Based on recombination frequencies between DSTM1 locus and the 25 markers, the DSTM1 locus was mapped on the long arm of chromosome II, between ATIPT2 and F24D13.7 CAPS markers. These two markers, at a distance of 169,926 bp from each other, showed the lowest recombination frequency (24\%). The location and recombination percentages of all markers are shown in an AGI (bp) map (Figure 5).

\section{Discussion and conclusion}

Systemic movement of TMV-U1 was studied in the Arabidopsis Uk-4 and Col-0 ecotypes presenting different rates of systemic infection. The delay in TMV-U1 systemic infection observed in Col-0 occurs at the long-distance movement stage, since CP accumulation in inoculated leaves was similar in both ecotypes (Figure 1). Systemic viral movement delay is not associated with a restriction given by a hypersensitive response, since necrotic lesions are not observed in the Col-0 ecotype. In previous investigations, the expression of resistance markers such as PR-1 had not been detected in Arabidopsis infected by TMV-U1 $[27,16]$. Therefore, this movement restriction indicates a passive response of the plant to the pathogen.

A detailed study of viral infection progress in different plant tissues using electron microscopy revealed that curved virions were present in the vascular tissues of petioles from inoculated leaves and stems of Col-0 plants. However normal rigid rod particles were present in the mesophyll cells of apical leaves, identical to those visualised in the mesophyll cells of inoculated leaves. These

Table 2: Genetic analysis of the delay in systemic movement of TMV-UI in Col-0

\begin{tabular}{|c|c|c|c|c|}
\hline Cross $^{a}$ & Fast movement & Delayed movement & Total & $\chi^{2 c}$ \\
\hline FI Uk-4 × Col- $0^{b}$ & 60 & 0 & 60 & - \\
\hline FI Col-0 × Uk-4 & 50 & 0 & 50 & - \\
\hline F2 Uk-4 × Col-0 & 198 & 79 & 277 & 1.8 \\
\hline F2 Col-0 × Uk-4 & 82 & 30 & 112 & 0.76 \\
\hline
\end{tabular}

a: The female parent is represented first in the cross. Six week-old FI and F2 plants were inoculated and the fast or delayed movement phenotype was determined in infected plants by means of Western blot at $12 \mathrm{dpi}$.

b: The presented data corresponds to one pair of reciprocal crosses.

c: The values of $\chi^{2}$ and $p$ were calculated to test the probability that this data collected in the segregated population corresponds to the expected values for segregation of 3:I for a single recessive locus that is responsible of delay in systemic movement of TMV-UI in Col- 0 . In both cases $p>$ 0.05 . 


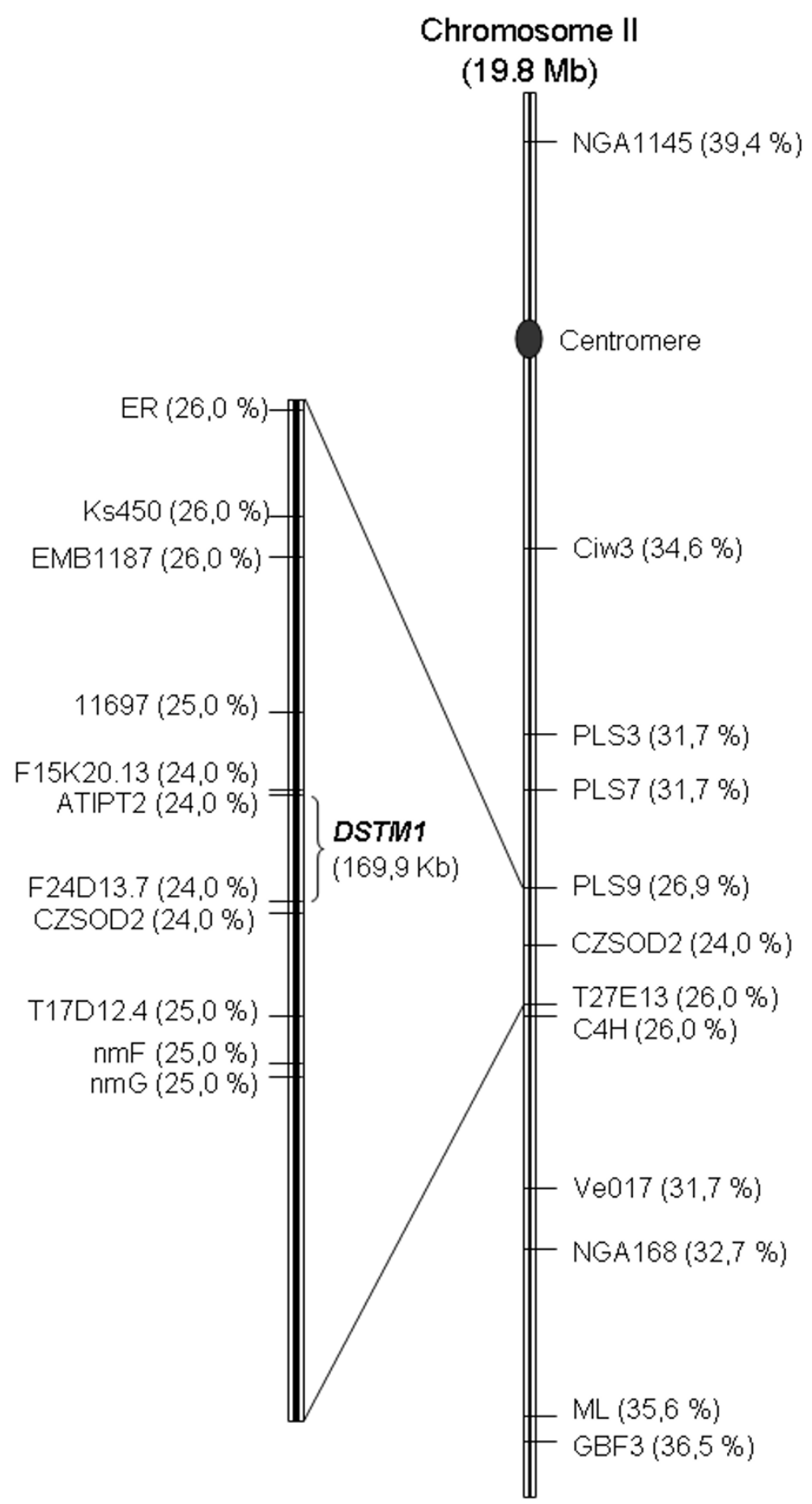

\section{Figure 5}

Location of DSTMI on chromosome II. Chromosome II map showing SSLP and CAPS molecular markers and the recombination percentages observed in mapping the trait of delay in systemic TMV-UI movement. An enlarged view of the DSTMI region is shown on the left. 
abnormal structures occur in a strain-specific manner, since the crucifer infecting TMV-Cg strain, which moves easily through the Col-0 plants (as in all ecotypes tested, [16]) always presented normal rigid rods in the stems of infected plants. This irregular virion shape may be related to the delayed movement in Col-0 plants. Viral entry and exit from phloem elements are the most critical points in systemic virus movement [1]. Inside phloem cells, protein synthesis or replication does not occur. Prior works have suggested that entry and exit from the vascular tissues could require a different set of host factors than those acting in the other infected tissues [1]. Thus, the vascular zone of Col-0 ecotypes could, for instance, interfere with correct viral assembly, stability or entry into the vascular tissue from the infected leaf. Nevertheless, when the virus exits the phloem and enters the mesophyll cells in systemic tissues, its structure assembles correctly again. Moreover, we demonstrated that the curved virions isolated from infected Col-0 plants were infective.

The phenotypic differences observed between the Uk-4 and Col-0 ecotypes prompted us to look for a host factor which could be related to this delay of systemic virion movement. Genetic crosses demonstrated that this delay is a recessive trait, since the rate of systemic movement was normal in all $\mathrm{F}_{1}$ plants, and is probably controlled by a monogenic nuclear locus. This locus was named DSTM1 for Delayed Systemic Tobamovirus Movement 1 and was mapped on the long arm of chromosome II, between sections 11,832,469 - 12,002,395 bp of Arabidopsis Col-0, using molecular markers. According to the Arabidopsis genome database (TAIR; http://www.arabidopsis.org) this region contains 43 loci and most of the genes within this region are unknown or putatively assigned. Among these unknown genes, four are related to transport function, one is involved in cell wall biosynthesis (a gluconyl transferase) and another encodes a protein with fucosidase activity. All of these functions are related to viral movement [28]. Whether if any of these loci is functionally responsible for the delayed viral movement phenotype, for instance interfering with the entrance into the vascular system, remains to be determined. Alternatively, the locus could participate in the stability or correct assembly of viral particles in the vascular tissue. This type of restriction leads to a passive resistance [29], because viral movement is a consequence of the absence of a host factor.

Other loci affecting systemic viral movement in a dominant or semi-dominant way in Arabidopsis thaliana have been identified and characterised. As in the present study, most are specific to one particular virus, since the infective process of the related Tobamovirus TMV-Cg is not affected in Col-0. Several other loci are related to restrictions in systemic movement [30]. For example, the VSM1 locus, although dominant, restricts Turnip vein clearing tobamovi- rus (TVCV) systemic movement at the level of phloem entry or exit [31]. In the Col-0 ecotype, two loci RTM1 and RTM2 have been proven to be responsible for restriction of Tobacco etch virus systemic movement. These loci were mapped to chromosomes I and $\mathrm{V}$ respectively and their products were localised in the phloem [14,15,32]. However neither direct nor indirect interactions between these proteins and virions have been found. Higher resolution mapping of DMST1 will lead to precise identification of the gene responsible for the delay in systemic TMV-U1 movement. This undoubtedly will contribute to the understanding of the complex interactions between virus and hosts leading to efficient infections, and therefore, for understanding resistance development.

\section{Authors' contributions}

CS participated in the design of the study, carried out the electron microscopy, hybridisation assays, genetic crosses and genetic marker analysis. JGC carried out the mapping on the $\mathrm{F}_{2}$ population, genetic marker design and participated in drafting the manuscript. FJ and PM collaborated in phenotypic population studies by immunoblots and mapping. CM conducted plant inoculation and together with JTM, collaborated in drafting the manuscript. PAJ designed the experimental procedure, was involved in revising the manuscript critically for important intellectual content and gave final approval of the version to be published. All authors read and approved the final manuscript.

\section{Acknowledgements}

This work was supported by Fondecyt project 1040789 to PAJ and a 2002 CONICYT-Doctoral fellowship to CS. The authors thank Dr. Roger Beachy for his assistance in CS work and the Millennium Nucleus for Plant Functional Genomics (P06-009F) and Juanita Larraín-Linton for her assistance in language support.

\section{References}

I. Carrington J, Kasschau K, Mahajan S, Schaad M: Cell-to-cell and long-distance movement of viruses in plants. Plant Cell I996, 8:1669-I68I.

2. Creager A, Scholthof KB, Citovsky V, Scholthof HB: Tobacco Mosaic Virus: pioneering research for a century. Plant Cell 1999, I I:301-308.

3. Knapp E, Lewandowski D: Tobacco mosaic virus, not just a single component virus anymore. Molecular Plant Pathology 200I, 2:I17-123.

4. Fujiki M, Kawakami S, Kim RW, Beachy RN: Domains oftobacco mosaic virus movement protein essential for its membraneassociation. Journal of General Virology 2006, 87:2699-2707.

5. Boyko V, Hu Q, Seemanpillai M, Ashby J, Heinlein M: Validation of microtubule-associated tobacco mosaic virus RNA movement and involvement of microtubule-aligned particle trafficking. The Plant Journal 2007, 5 I:589-603.

6. Guenoune-Gelbart D, Labaum M, Sagi G, Levy A, Epel B: Tobacco mosaic virus (TMV) replicase and movement protein function synergistically in facilitating TMV spread by lateral diffusion in the plasmodesmal desmotubuleof Nicotiana benthamiana. Molecular Plant Microbe Interactions 2008, 2 I (3):335-345

7. Kunkel BN: A useful weed put to work: Genetic analysis of disease resistance in Arabidopsis thaliana. Trends Genet 1996, 12:63-69. 
8. Yoshii M, Yoshioka N, Ishikawa M, Naito S: Isolation of an Arabidopsis thaliana mutant in which accumulation of Cucumber Mosaic Virus coat protein is delayed. Plant Journal 1998, 13:211-219.

9. Callaway A, Wennuan L, Vyacheslav A, Stenzler L, Zhao J, Wettlaufer $S$, Jayakumar $P$, Howell $S$ : Characterisation of Cauliflower Mosaic Virus (CaMV) resistance in virus-resistant ecotypes of Arabidopsis. Molecular Plant Microbe Interactions 1996, 9:810-818.

10. Cooley MB, Pathirana S, Wu HJ, Kachroo P, Klessig DF: Members of the Arabidopsis HRTIRPP8 Family of Resistance Genes Confer Resistance to Both Viral and Oomycete Pathogens. Plant Cell 2000, I 2(5):663-677.

II. Takahashi M, Sasaki Y, Ida S, Morikawa H: Nitrite Reductase Gene Enrichment Improves Assimilation of $\mathbf{N O}_{2}$ in Arabidopsis. Plant Physiology 200I, I 26:73I-74I.

12. Yamanaka $S$, Ishihara M, Sugiyama J: Structural modification of bacterial cellulose. Cellulose 2000, 7(3):213-225.

13. Tsujimoto Y, Muraga T, Ohshima K, Yano M, Ohsawa R, Goto DB, Naito S, Ishikawa M: Arabidopsis Tobamovirus multiplication (TOM) 2 locus encodes a transmembrane protein that interacts with TOM I. The EMBO Journal 2003, 22:335-343.

14. Chisholm S, Mahajan S, Whitham S, Carrington J: Cloning of the Arabidopsis RTMI gene, which control restriction of longdistance movement of tobacco etch virus. Proceeding of the National Academy of Science 2000, 97:489-494.

15. Chisholm S, Parra M, Anderberg RJ, Carrington J: Arabidopsis RTMI and RTM2 genes function in phloem to restrict longdistance movement of tobacco etch virus. Plant Physiology 2001 127:1667-1675.

16. Arce-Johnson P, Medina C, Padgett H, Huanca W, Espinoza C: Analysis of local and systemic spread of the crucifer-infecting TMV-Cg virus in tobacco and several Arabidopsis thaliana ecotypes. Functional Plant Biology 2003, 30:40I-408.

17. Guzmán P, Ecker J: Exploiting the triple response of Arabidopsis to identify ethylene-related mutants. The Plant Cell 1990, 2:513-523.

18. Bruening G, Beachy $R N$, Scalla $R$, Zaitlin $M$ : In vitro and in vivo translation of the ribonucleic acids of cowpea strain of tobacco mosaic virus. Virology 1976, $71: 498-517$.

19. Pereda S, Ehrenfeld KN, Medina C, Delgado J, Arce-Johnson P: Comparative analysis of TMV-UI and TMV-Cg detection methods in infected Arabidopsis thaliana. Journal of Virology Methods 2000, 90(2): $135-142$.

20. Lartey R, Ghoshroy S, Ho J, Citovsky V: Movement and subcellular localization of a tobamovirus in Arabidopsis. The Plant Journal 1997, I 2(3):537-545.

21. Epstein MA, Holt SJ: The localization by electron microscopy of HeLa cell surface enzymes splitting adenosine triphosphate. The Journal of Cell Biology 1963, 19:325-326.

22. Reynolds ES: The use of lead citrate at high $\mathbf{p H}$ as an electronopaque stain in electron microscopy. The Journal of Cell Biology 1963, I7:208-212.

23. Muramoto T, Kohchi T, Yokota A, Hwang I, Goodman HM: The Arabidopsis photomorphogenic mutant hyl is deficient in phytochrome chromophore biosynthesis as a result of a mutation in a plastid heme oxygenase. The Plant Cell 1999, I I:335-347.

24. Matsumoto $\mathrm{N}$, Okada K: A homeobox gene, PRESSED FLOWER, regulates lateral axis-dependent development of Arabidopsis flowers. Genes and development 200I, 15:3355-3364.

25. Konieczny A, Ausubel F: A procedure for mapping Arabidopsis mutations using co-dominant ecotype-specific PCR-based markers. The Plant Journal 1993, 4:403-410.

26. Bell CJ, Ecker JR: Assignment of thirty microsatellite loci to the linkage map of Arabidopsis. Genomics 1994, 19:137-I44.

27. Dardick C, Gloem S, Culver J: Susceptibility and symptom development in Arabidopsis thaliana to tobacco mosaic virus is influenced by virus cell-to cell movement. Molecular Plant Microbe Interactions 2000, 13:1 139-1 I 44.

28. Chen MH, Citovsky V: Systemic movement of a tobamovirus requires host cell pectin methyltransferase. The Plant Journal 2003, 35:386-392.

29. Lee S, Stenger D, Bisaro D, Davis K: Identification of loci in Arabidopsis that confer resistance to geminivirus infection. The Plant Journal 1994, 6:525-535.
30. Takahaschi H, Susuki M, Natsuaky K, Shigyo T, Hino K, Teraoka T, Hooskawa D, Ehara $Y$ : Mapping the virus and host genes involved in the resistance response in cucumber mosaic virus-infected Arabidopsis thaliana. Plant and Cell Physiology 200 I, 42:340-347.

31. Lartey R, Ghoshroy S, Citovsky V: Identification of an Arabidopsis thaliana mutation (vsm I) that restricts systemic movement of tobamoviruses. Molecular Plant Microbe Interactions 1998, I I:706-709.

32. Whitham S, Anderberg R, Chisholm S, Carrington JC: Arabidopsis RTM2 gene is necessary for specific restriction of tobacco etch virus and encodes an unusual small heat shock-like protein. The Plant Cell 2000, I 2:569-582.
Publish with Biomed Central and every scientist can read your work free of charge

"BioMed Central will be the most significant development for disseminating the results of biomedical research in our lifetime. "

Sir Paul Nurse, Cancer Research UK

Your research papers will be:

- available free of charge to the entire biomedical community

- peer reviewed and published immediately upon acceptance

- cited in PubMed and archived on PubMed Central

- yours - you keep the copyright 